\title{
Boarding House Information System Based on Geographic Location in Sidoarjo
}

\section{Sistem Informasi Indekos Mahasiswa Berbasis Lokasi Geogrfis di Sidoarjo}

\author{
Amirrudin Hamzah ${ }^{1}$, Yulian Findawati ${ }^{2}$ \\ \{amirudeen.hamzah@gmail.com ${ }^{1}$, yulianfindawati@umsida.ac.id ${ }^{2}$ \}
}

Program Studi Informatika, Fakultas Sains \& Teknologi Universitas Muhammadiyah Sidoarjo

\begin{abstract}
According to data from BPS Sidoarjo and Pangkalan Dikti 2020, Sidoarjo has around 16.000 active college student and around 28.000 migrant that on productive age at 19-29 to take an education. Migrant college student that taking a college on Sidoarjo always left their home to stay in a temporary-permanent place in Sidoarjo. This research intended to helps college student to find proper boarding house and close to their college. A method that used is compiling boarding house data in Sidoarjo and processing that data into information for college student and boarding house owner. The research resulting an information system with geographic based that loads a boarding house data in Sidoarjo and some feature to ease the college student to get a boarding house properly. The benefit of this research for college student is to decrease their effort to get a matching \& close boarding house to their college and for boarding house owner is for a marketing media for their boarding house
\end{abstract}

Keywords - boarding house; information system; college student; residence; dwelling; college

\begin{abstract}
Abstrak. Mengacu pada data dari BPS Sidoarjo dan Pangkalan Dikti 2020, Sidoarjo memiliki sekitar 16.000 mahasiswa aktif dan sekitar 28.000 migran berusia produktif 19-29 untuk menempuh jenjang pendidikan. Mahasiswa migran yang menempuh pendidikan di Sidoarjo seringkali meninggalkan daerah asalnya untuk tinggal di hunian tetap di Sidoarjo. Penelitian ini bertujuan untuk membantu mahasiswa menemukan indekos sesuai dengan parameter pencarian serta dekat dengan kampus mahasiswa. Metode yang digunakan mengkompulir data indekos di Sidoarjo dan mengolah data tersebut menjadi sistem informasi bagi mahasiswa dan pemilik indekos. Hasil penelitian menghasilkan sistem informasi berbasis lokasi geografis yang memuat data indekos di Sidoarjo serta beberapa fitur untuk memudahkan mahasiswa mencari indekos sesuai parameter. Manfaat penelitian ini bagi mahasiswa dapat memangkas usaha untuk mencari indekos yang dekat dengan kampusnya serta untuk pemilik indekos dapat sebagai media pemasaran indekosnya
\end{abstract}

Kata Kunci - indekos; sistem informasi; mahasiswa; tempat tinggal; kampus

\section{Pendahuluan}

Berdasarkan data dari BPS \& Pangkalan Dikti, Sidoarjo memiliki setidaknya 16.000 mahasiswa aktif yang di dalamnya berstatus migran[1][2][3]. Berdasarkan pengamatan personal penulis yang berstatus mahasiswa di kampus dengan jumlah mahasiswa terbanyak di Sidoarjo[4], mahasiswa yang berstatus migran banyak yang memutuskan menetap di Sidoarjo agar dekat dengan kampus. Salah satu tindakan yang pasti diambil oleh para migran sebelum memutuskan bertempat tinggal di tempat migran adalah mencari tempat tinggal terlebih dahulu dengan cara menyusuri kawasan kampus dan melakukan survei personal terhadap tempat yang akan ditinggali salah satunya tempat tinggal berjenis indekos.

Untuk itu penelitian ini dibuat guna memangkas usaha yang dilakukan pencari indekos yang berstatus mahasiswa migran agar lebih mudah dalam mencari indekos sesuai dengan parameter dan kampus mahasiswa. Berdasarkan penelitian terdahulu oleh Rama Adi Putra pada tahun 2018 dengan judul "Sistem Informasi Geografis Backpacker di Kota Malang Berbasis Android", penelitian ini berfokus pada bagaimana membangun SIG dengan pemetaan objek backpacker di Kota Malang. Penelitian ini menghasilkan aplikasi yang cukup baik berbasis mobile namun dengan objek yang spesifik untuk pengguna dengan latar belakang petualang.

Penelitian ini juga mengacu pada penelitian terdahulu oleh Yeremias Budi Liman Hege, Erna Kumalasari, dan Uning Lestari pada tahun 2013 dengan judul "Sistem Informasi Geografis Pelayanan Kesehatan di Kotamadya Yogyakarta Berbasis Web" yang menghasilkan sistem informasi geografis berbasis web yang dapat digunakan warga Yogyakarta untuk mengakses layanan kesehatan. Selain itu juga penelitian ini mengacu pada penelitian sebelumnya Eko Tresno Prabowo, Muhammad Sholeh, dan Catur Iswahyudi dengan judul "Sistem Informasi Geografis Dalam Pencarian Museum di Daerah Istimewa Yogyakarta" yang telah menghasilkan sistem informasi geografis berbasis web yang memetakan objek museum bagi warga Yogyakarta

Berdasarkan penelitian terdahulu yang dirujuk dan masalah yang dirumuskan, maka perlu dikembangkan sistem informasi indekos mahasiswa berbasis lokasi geografis dengan tujuan untuk mempermudah mahasiswa migran yang 
akan mencari tempat tinggal berjenis indekos di Sidoarjo sesuai dengan parameter personal dan dekat dengan kampus. Penelitian ini penting dilakukan mengingat jumlah mahasiswa di Sidoarjo cukup besar dan di dalam data tersebut terdapat mahasiswa berstatus migran yang akan mencari indekos.

\section{METODE}

\section{A. Teknik pengumpulan data}

\section{Literatur}

Metode ini dilakukan dengan mengunjungi repositori jurnal digital untuk mendapatkan literatur yang berkaitan dengan teori sistem informasi geografis.

\section{Canvasing}

Metode ini dilakukan dengan terjun langsung ke lapangan dan dari sumber daring untuk mendapatkan data indekos beserta kampus di Sidoarjo.

\section{B. Perancangan sistem}

Perancangan sistem memberikan gambaran umum tentang sistem yang akan dibangun. Menyajikan identifikasi komponen komponen sistem informasi yang akan dibangun secara detil.

\section{Use case diagram}

Use Case Diagram atau diagram kasus penggunaan adalah representasi paling sederhana dari interaksi pengguna dengan sistem yang menunjukkanhubungan antara pengguna dengan use case dimana pengguna terlibat. Use case diagram direpresentasikan dengan lingkaran atau oval[5]. Berikut adalah use case diagram dari sistem informasi geografis yang diteliti.

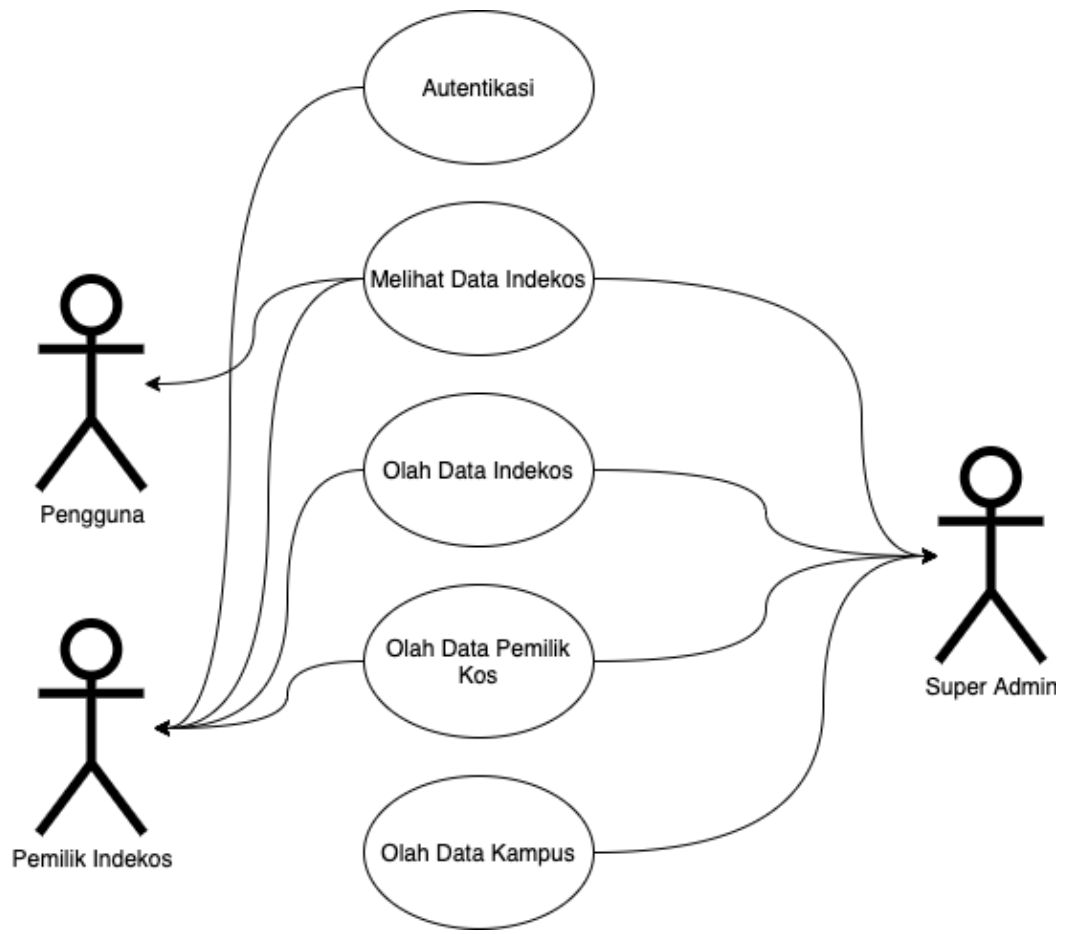

Gambar 1. Use Case Diagram

Diagram use case di atas terdiri dari 3 aktor dan 5 use case. Dengan masing masing use case dimiliki oleh masing masing aktor.

\section{Activity diagram}

Activity Diagram adalah representasi grafis dari alur kerja tahapan aktivitas dan aksi dengan dukungan untuk memilih, iterasi dan konkurensi dari sebuah sistem informasi. Berikut adalah activity diagram dari sistem informasi geografis yang diteliti[6]. 
Procedia of Engineering and Life Science Vol.1 No. 1 March 2021

Seminar Nasional \& Call for Paper Fakultas Sains dan Teknologi (SENASAINS $1^{\text {st }}$ )

Universitas Muhammadiyah Sidoarjo

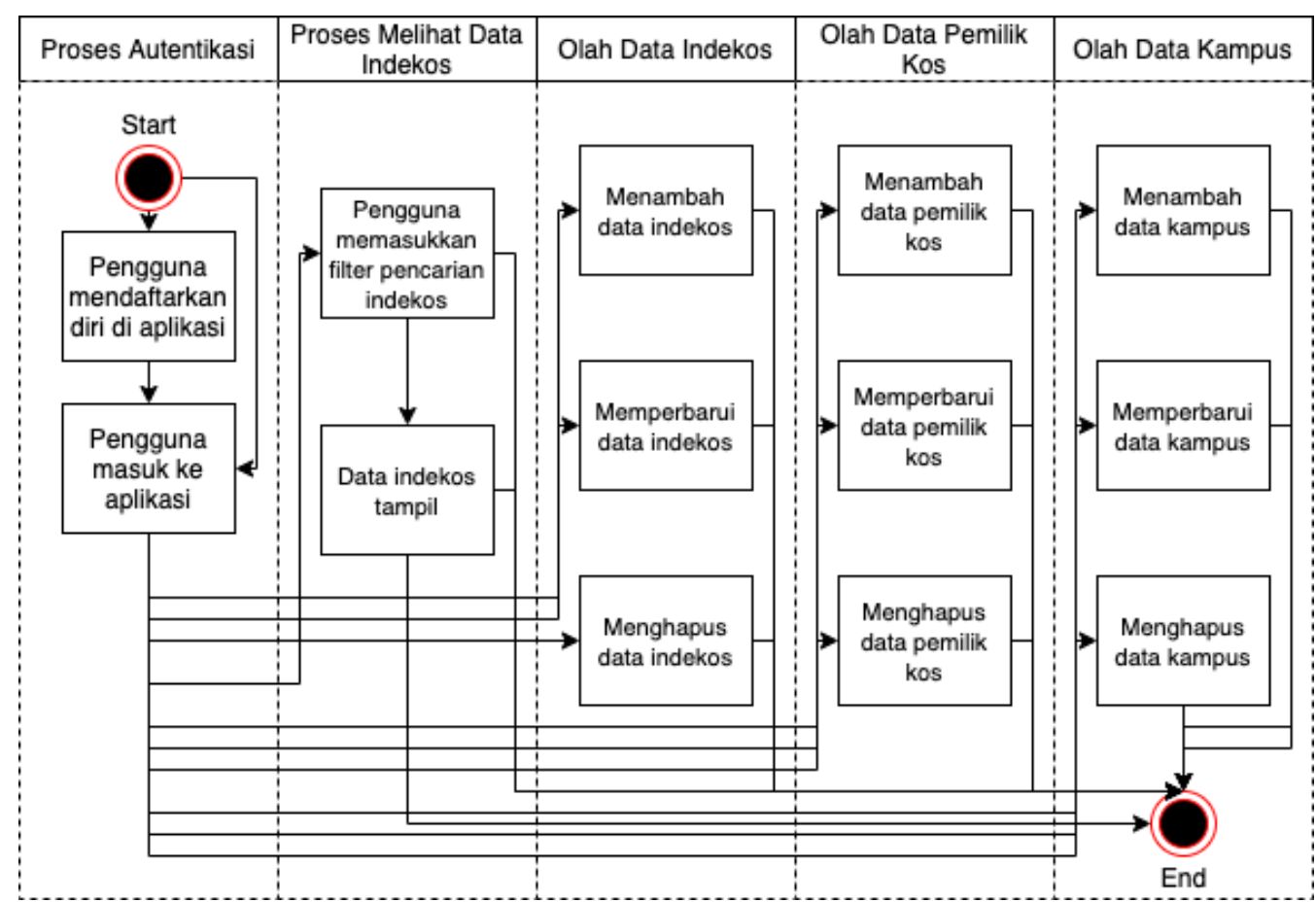

Gambar 2. Activity Diagram

Flowchart

Flowchart adalah tipe dari diagram yang merepresentasikan alur kerja atau proses[7]. Flowchart adalah diaram alur paling sederhana diantara diagram lain yang merepresentasikan alur kerja. Berikut adalah diagram alir dari sistem informasi geografis yang sedang diteliti

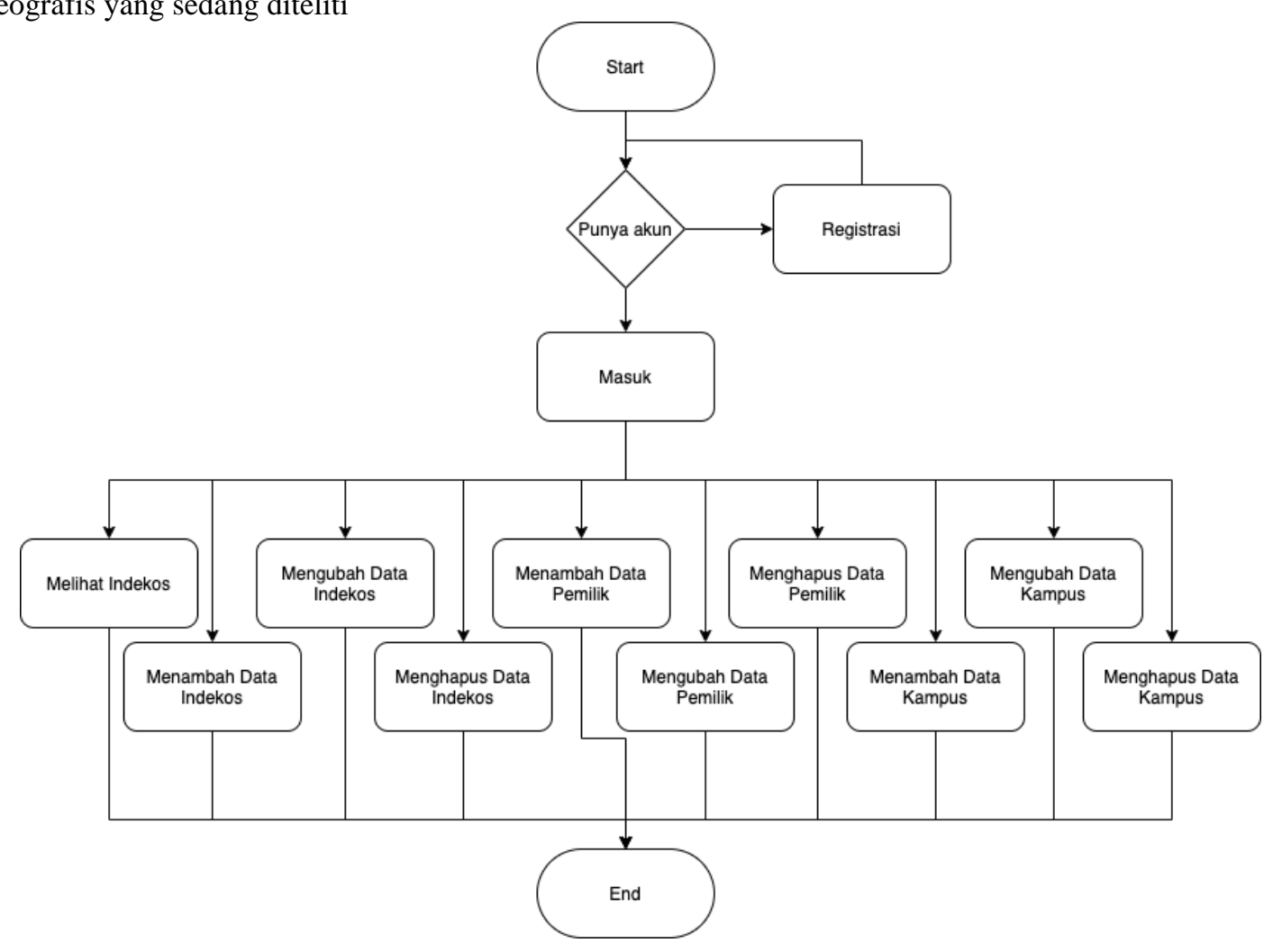

Gambar 3. Flowchart 
Data flow diagram

Data flow diagram adalah diagram untuk merepresentasikan aliran data dari sebuah sistem atau proses[8]. DFD juga menyediakan informasi tentang keluaran dan input dari setiap entitas dan proses itu sendiri. Data flow diagram tidak memiliki kontrol arus, tidak ada aturan keputusan dan tidak ada perulangan. Berikut adalah data flow diagram level 0 dan 1

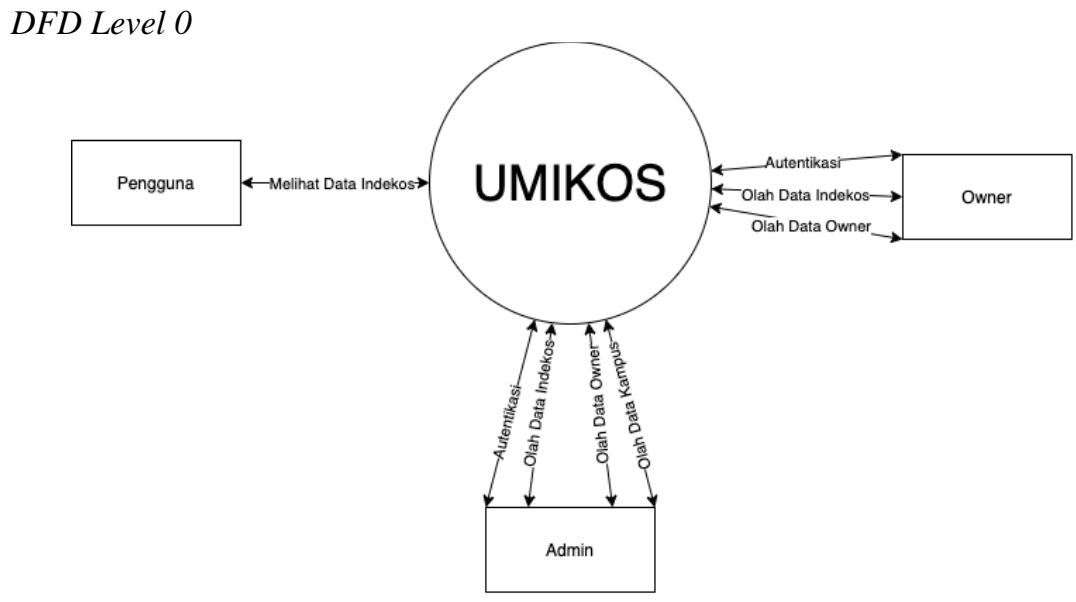

Gambar 4. DFD Level 0

DFD Level 0 menggambarkan secara umum gambaran besar dari Sistem Informasi Geografis yang akan dibangun. Di dalamnya terdapat 3 entitas utama yang masing masing memiliki relasi data dengan sistem.

DFD Level 1

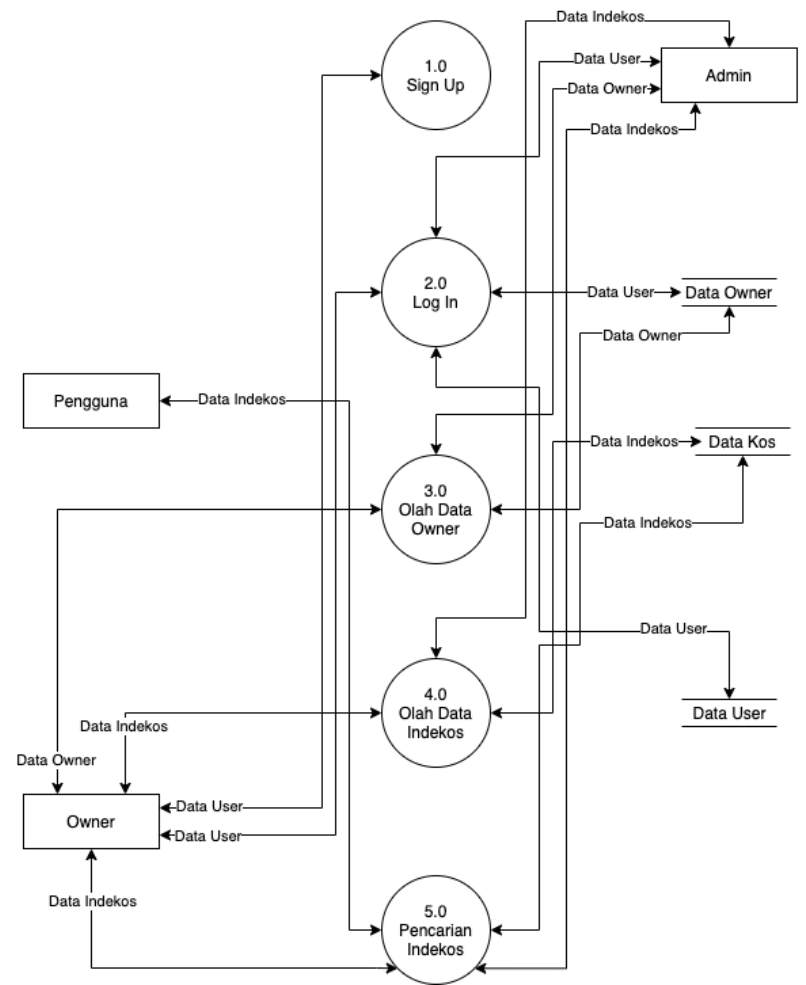

Gambar 5. DFD Level 1

DFD level 1 menggambarkan gambaran lebih detil dari DFD level 0. Pada DFD level 1 terdapat 5 proses dengan 3 data store serta 3 entitas yang masih ada dari DFD level 0. Dalam DFD level 1 diperjelas dengan aliran data dari masing masing entitas, proses hingga data store. 
Entity relationship diagram

ERD memberikan informasi relasi antar tabel di dalam sistem. Dalam sistem yang akan dibangun memiliki 3 tabel yaitu tb_indekos, tb_pemilik \& tb_user. Berikut adalah informasi relasi antar tabelnya

- tb_indekos - tb_pemilik : one to many

- tb_pemilik - tb_user : one to one
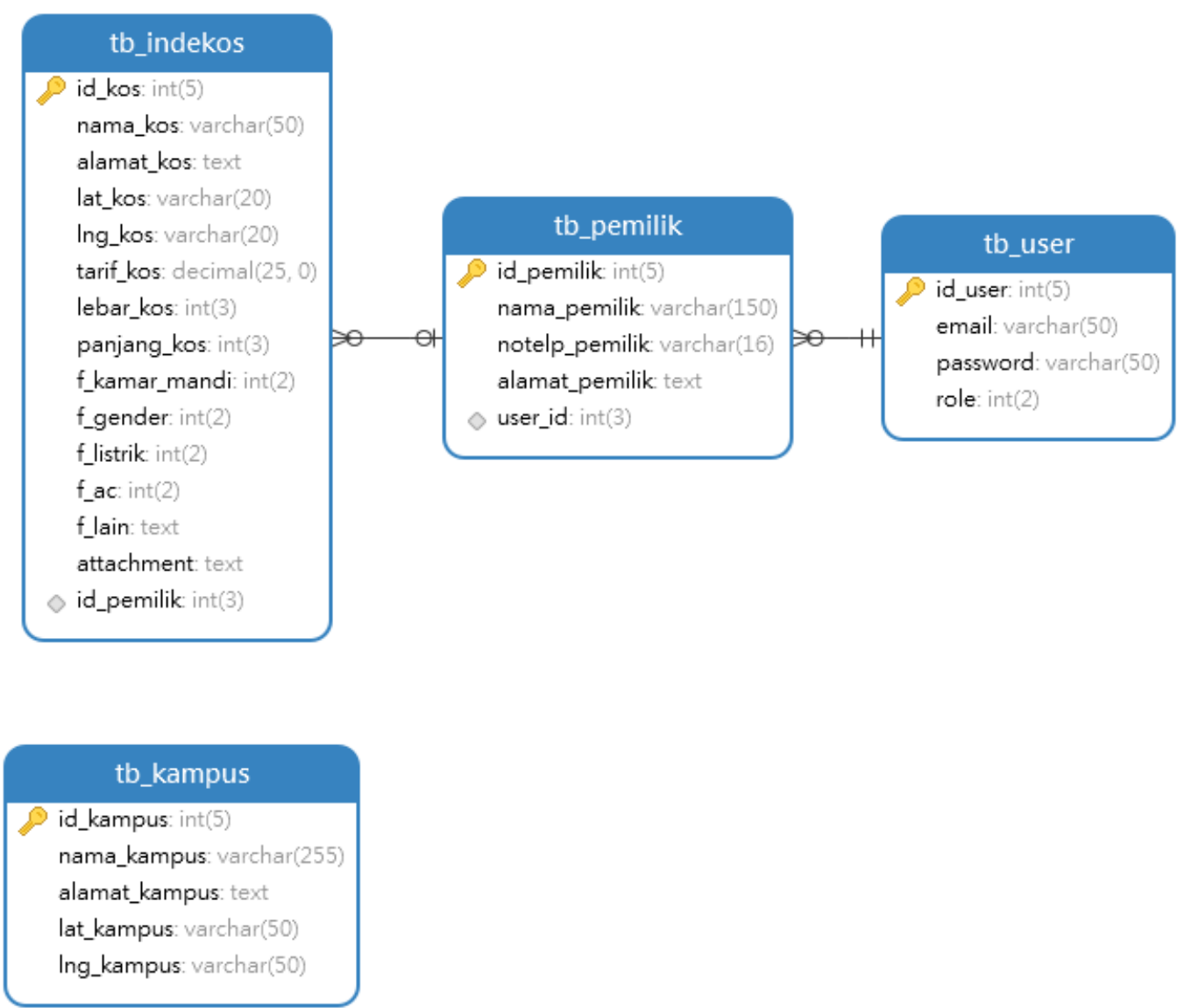

Gambar 6. ERD

Struktur tabel

Bagian ini menyajikan informasi lebih detil tentang struktur tabel yang ada pada sistem[9]. Terdapat 3 tabel yang digunakan dan berikut adalah struktur yang ada dalam tabel tabel tersebut :

Tabel 1. Struktur Tabel Indekos

\begin{tabular}{ll}
\hline Nama Kolom & Tipe Data \\
\hline id_kos & int(5) \\
\hline nama_kos & varchar(50) \\
\hline alamat_kos & text \\
\hline lat_kos & varchar(20) \\
\hline lng_kos & $\operatorname{varchar}(20)$ \\
\hline luas_kos & $\operatorname{int}(3)$ \\
\hline panjang_kos & $\operatorname{int}(3)$ \\
\hline f_kamar_mandi & $\operatorname{int}(2)$ \\
\hline f_gender & $\operatorname{int}(2)$ \\
\hline f_listrik & $\operatorname{int}(2)$ \\
\hline
\end{tabular}


Procedia of Engineering and Life Science Vol.1 No. 1 March 2021

Seminar Nasional \& Call for Paper Fakultas Sains dan Teknologi (SENASAINS $1^{\text {st}}$ )

Universitas Muhammadiyah Sidoarjo

\begin{tabular}{ll}
\hline f_ac & $\operatorname{int}(2)$ \\
\hline f_lain & text \\
\hline attachments & text \\
\hline id_pemilik & $\operatorname{int}(3)$ \\
\hline
\end{tabular}

Tabel 2. Struktur Tabel Pemilik

\begin{tabular}{ll}
\hline Nama Kolom & Tipe Data \\
\hline id_pemilik & $\operatorname{int}(5)$ \\
\hline nama_pemilik & varchar(150) \\
\hline notelp_pemilik & varchar(16) \\
\hline alamat_pemilik & text \\
\hline user_id & $\operatorname{int}(3)$ \\
\hline
\end{tabular}

Tabel 3. Struktur Tabel User

\begin{tabular}{ll}
\hline Nama Kolom & Tipe Data \\
\hline id_user & $\operatorname{int}(5)$ \\
\hline username & $\operatorname{varchar}(50)$ \\
\hline password & $\operatorname{varchar}(50)$ \\
\hline Role & $\operatorname{int}(2)$ \\
\hline
\end{tabular}

Tabel 4. Struktur Tabel Kampus

\begin{tabular}{ll}
\hline Nama Kolom & Tipe Data \\
\hline id_kampus & int(5) \\
\hline nama_kampus & varchar(225) \\
\hline alamat_kampus & text \\
\hline lat_kampus & varchar(50) \\
\hline lng_kampus & varchar(50) \\
\hline
\end{tabular}

\section{Hasil dan Pembahasan}

\section{A. Hasil penelitian}

Hasil penelitian ini adalah sebuah Sistem Informasi Indekos Mahasiswa Berbasis Geografis di Sidoarjo

\section{B. Pembahasan}

Pada aplikasi ini menyediakan fitur fitur di setiap halamannya antara lain :

\section{Halaman utama}

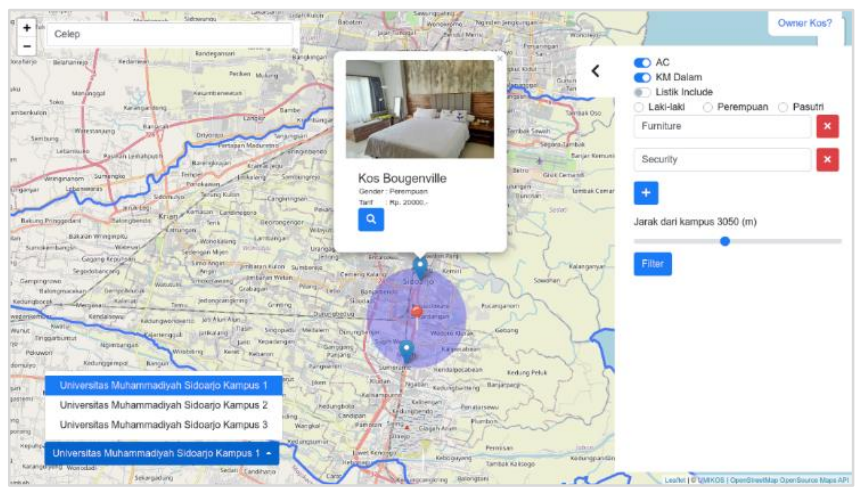

Gambar 7. Halaman Landing 
Pada saat pengguna mengakses aplikasi pertama kali akan diarahkan ke halaman landing. Di halaman landing terdapat beberapa elemen dan fitur yang dapat digunakan diantaranya :

- Peta Sidoarjo, peta ini akan memuat lokasi indekos dan radius yang sedang dicari. Peta ini sudah dilengkapi batasan kabupaten Sidoarjo agar lebih informatif. Serta peta ini dapat diperbesar dan diperkecil[10]

- Panel filter, panel ini memuat beberapa filter yang dapat digunakan pengguna untuk mencari indekos sesuai keinginan. Terdapat 3 filter wajib dan pengguna dapat menambahkan filter tambahan hingga tak terbatas.

- Radius, pengguna juga dapat menentukan seberapa jauh jarak yang ditempuh dari kampus di Sidoarjo melalui panel filter[11]

- Kampus, pengguna dapat memilih kampus yang tersedia untuk mengarahkan radius yang akan dicari

- Kotak Pencarian, kotak pencarian ini dapat mencari berdasarkan nama indekos, pemilik atau alamat indekos

- Mini-info Pin, menampilkan informasi singkat dari indekos yang muncul untuk selanjutnya dapat dilihat lebih detil.

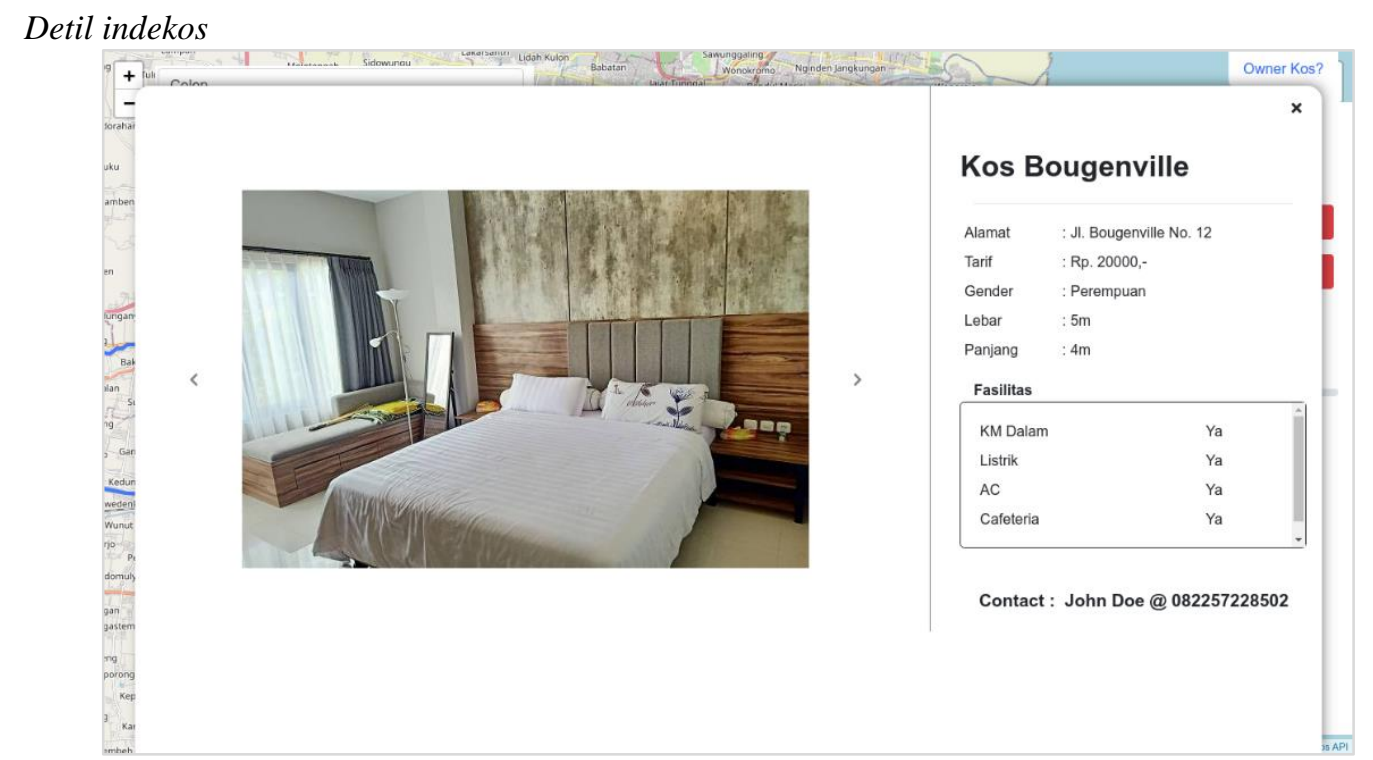

Gambar 8. Detil Indekos

Pada halaman ini akan muncul info detil dari indekos yang disorot dari nama indekos hingga kontak pemilik indekos. Halaman ini berupa popup yang akan muncul jika tombol detil pada mini-info pin diklik.

\section{Pengujian aplikasi}

Sistem Informasi ini diujicobakan pada 13 pengguna dengan status 12 orang sebagai mahasiswa dan 1 orang sebagai pemilik indekos. Masing masing penguji juga menggunakan platform serta browser yang berbeda beda. Berikut adalah hasil pengujian dan kuesioner penguji.

Tabel 5. Tabel Kuesioner Pengujian

\begin{tabular}{clccccc}
\hline No & \multicolumn{1}{c}{ Item Kuesioner } & $\mathbf{1}$ & $\mathbf{2}$ & $\mathbf{3}$ & $\mathbf{4}$ & $\mathbf{5}$ \\
\hline 1 & Apakah UMIKOS memiliki tampilan yang interaktif? & 0 & 1 & 0 & 3 & 9 \\
\hline 2 & Apakah tata letak UMIKOS mudah dipahami? & 0 & 0 & 1 & 1 & 11 \\
\hline 3 & $\begin{array}{l}\text { Apakah peta Sidoarjo untuk memuat indekos pada UMIKOS } \\
\text { dapat dipahami? }\end{array}$ & 0 & 0 & 0 & 3 & 10 \\
\hline 4 & $\begin{array}{l}\text { Apakah fitur pencarian indekos pada UMIKOS sangat } \\
\text { membantu? }\end{array}$ & 0 & 0 & 0 & 3 & 10 \\
\hline 5 & Apakah informasi terkait indekos pada UMIKOS informatif? & 0 & 1 & 0 & 2 & 10 \\
\hline 6 & Apakah navigasi menu pada UMIKOS mudah digunakan? & 0 & 0 & 0 & 4 & 9 \\
\hline 7 & $\begin{array}{l}\text { Secara keseluruhan apakah aplikasi UMIKOS mudah } \\
\text { digunakan? }\end{array}$ & 0 & 0 & 1 & 1 & 11 \\
\hline 8 & $\begin{array}{l}\text { Apakah aplikasi UMIKOS memiliki fungsi dan kegunaan } \\
\text { sesuai yang diharapkan? }\end{array}$ & 0 & 0 & 1 & 2 & 10 \\
\hline
\end{tabular}


Procedia of Engineering and Life Science Vol.1 No. 1 March 2021

Seminar Nasional \& Call for Paper Fakultas Sains dan Teknologi (SENASAINS 1st)

Universitas Muhammadiyah Sidoarjo

\begin{tabular}{llllccc}
\hline 9 & $\begin{array}{l}\text { Apakah Anda mendukung UMIKOS untuk mengudara pada } \\
\text { masyarakat? }\end{array}$ & 0 & 0 & 0 & 2 & 11 \\
\hline 10 & Berapa skala rating yang Anda berikan untuk UMIKOS? & 0 & 0 & 0 & 1 & 12 \\
\hline & Total & 0 & 2 & 3 & 22 & 103 \\
\hline
\end{tabular}

Berdasarkan kuesioner pengujian dari responden yang terkait dengan sistem, maka diperoleh skor 5 dengan jumlah poin 103, skor 4 dengan jumlah poin 22, skor 3 dengan jumlah poin 3, dan skor 2 dengan jumlah poin 2 . Dapat disimpulkan bahwa hasil penelitian dapat berjalan baik sesuai dengan pengujian pengguna.

\section{KESIMPULAN}

Dengan adanya sistem informasi geografis ini, pengguna atau mahasiswa yang berstatus migran dan pemilik indekos dapat mendapat serta mengunggah informasi indekosnya secara mudah dan dekat dengan kampus di Sidoarjo berdasarkan nilai pengujian oleh mahasiswa \& pemilik kos. Sistem yang dibuat selain untuk mahasiswa migran, juga dapat digunakan oleh pemilik indekos sebagai sarana pemasaran indekos miliknya berdasarkan nilai pengujian oleh mahasiswa \& pemilik kos.

\section{REFERENSI}

[1] Kemenristekdikti, "Pencarian Perguruan Tinggi," Kemenristekdikti, 2020

[2] "Perkembangan Penduduk Menurut Kecamatan," BPS Sidoarjo, Sidoarjo, 2019

[3] S. P, "Satu Data untuk Pembangunan Kabupaten Sidoarjo," BPS Sidoarjo, Sidoarjo, 2019.

[4] UMSIDA, "Statistik Umsida," Akademik Umsida, Sidoarjo, 2018.

[5] G. W. Sasmito, "Penerapan Metode Waterfall Pada Desain Sistem Informasi Geografis Industri Kabupaten Tegal," 2017.

[6] H. Kurniawan and M. R. Tanjung, "Sistem Informasi Geografis Objek Wisata Alam di Provinsi Sumatera Utara Berbasis Mobile Android," 2017.

[7] S. Maharani, D. Apriani and H. Kridalaksana, "SISTEM INFORMASI GEOGRAFIS PEMETAAN MASJID DI SAMARINDA BERBASIS WEB," 2017.

[8] Hutrianto. "Sistem Informasi Geografis Penderita Malaria pada Kelurahan Cereme Taba Kota Lubuklinggau," 2019.

[9] I. F. Astuti and A. Anugerah, "Sistem Informasi Geografis Berbasis Web Pemetaan Lokasi Toko Oleh Oleh Khas Samarinda," 2016.

[10] "OpenStreetMap," OpenStreetMap, 2021. [Online]. Available: https://www.openstreetmap.org/help. [Accessed 2021].

[11] "Leaflet Reference," Leaflet, 2021. [Online]. Available: https://leafletjs.com/reference-1.7.1.html. [Accessed 2021]. 